\title{
Competency-based training for physicians: Are we doing no harm?
}

\author{
Cynthia R. Whitehead MD PhD, Ayelet Kuper MD DPhil
}

Competing interests: Cynthia Whitehead has received grants from the Associated Medical Services Phoenix Fellowship and the Canadian Institutes of Health Research (CIHR). Ayelet Kuper has received a grant from the Associated Medical Services Phoenix Fellowship and salary support through a New Investigator Salary Award from CIHR.

This article has been peer reviewed.

Correspondence to: Cynthia Whitehead, cynthia.whitehead @wchospital.ca

CMAJ 2015. DOI:10.1503 /cmaj.140873
$\mathrm{T}$ he past decade has witnessed a radical shift in medical education. Most current Canadian physicians were trained in a time-based system, moving from one monthly rotation to another. However, medical education is rapidly transforming into an outcomes-based model in which the physician is defined by a set of measurable abilities called competencies. ${ }^{1}$

In this model, a trainee must achieve a list of competencies rather than spend fixed numbers of months on particular rotations. This approach may be appealing: How better to be accountable to our patients and society than by setting clear standards and then ensuring that they have been met? In outcomes-based models, educators must comprehensively teach and assess all defined competencies. They must also ensure that competency frameworks are complete, including clear standards not only for knowledge and technical skills but also for complex physician attributes, such as compassion, tolerance of uncertainty and cognitive flexibility. Competency models are hailed as a superior way to train doctors. Are they? To be honest, it will not be easy to find out.

Canada is an international leader in competency-based education. The Royal College of Physicians and Surgeons of Canada created the CanMEDS $^{2}$ competency framework with seven named roles for specialist physicians: Medical Expert, Communicator, Collaborator, Manager, Health Advocate, Scholar and Professional. Recently, The College of Family Physicians of Canada adapted the CanMEDS roles and incorporated them into its Triple C Curriculum. ${ }^{3}$ These competency frameworks are used for accreditation of Canadian residency programs

\section{KEY POINTS}

- Medical educators acknowledge important challenges associated with teaching and assessing certain CanMEDS roles in outcome-based education.

- Ensuring that competencies are sufficiently comprehensive to capture the many complex facets of high-quality medical work is no easy task.

- Because very little is known about the effects - both intended and unintended - of this education model, ongoing research will be essential. and play an important role in Canadian medical schools. They have also begun to appear in continuing education and, in the future, may be used by both colleges for assessing the maintenance of competence in all practising physicians.

Because competency frameworks have been mandated and enacted, it is too late to ask if they are better than time-based models. Comprehensive evaluations of the existing programs were not made by either college before the competencybased changes were implemented; therefore, there is no way to know how well the old ways of doing things worked. In addition, evaluating large educational interventions is hard because it is difficult to separate the effects of curricular innovations from the multitude of other constantly changing factors (e.g., health systems, funding models, advances in technology, societal structures and reform of duty hours) that influence the attitudes and practices of trainees. ${ }^{4}$ Given these realities, medical educators should first focus on identifying potential challenges in competency-based education and then focus on mitigating any problems.

What might be some of those challenges? One obvious challenge is that educators must find effective ways to teach ALL of the competencies, not just biomedical knowledge. In previous time-based models, educators relied on residents having enough experiences over time to develop mastery in complex areas. Of course, this was problematic, as it merely assumed that such mastery would occur after sufficient training time. However, the recent Future of Medical Education in Canada report on postgraduate training clearly acknowledges that educators lack fundamental knowledge about how to teach many CanMEDS roles. ${ }^{5}$ Instruction about roles such as Advocate, Professional, Collaborator and Communicator also requires knowledge of the social sciences and humanities that most medical educators (who were trained in a biomedical model) lack. ${ }^{6}$ Moreover, most current (largely psychometric) assessment methods simply do not make sense for the multiple CanMEDS roles that involve social interaction. ${ }^{7}$ Mandates to teach and assess difficult social constructs will 
not accomplish anything unless relevant and effective teaching methods are in place.

Because everything that is taught and assessed in a competency-based model must be named and described, educators must be certain that the list of competencies incorporates absolutely everything that a good doctor needs to do and be. However, complex attributes, such as compassion, integrity or curiosity, are multifaceted; therefore, comprehensive definitions for these attributes will likely remain elusive. Furthermore, requiring busy clinical educators to teach and assess the myriad specific items outlined in competency frameworks will inevitably divert their attention away from concepts that are harder to name and define. Learners may then focus on simpler areas that they know their teachers can easily assess. If competency models do not easily incorporate complex attributes, how can educators ensure that these attributes are prominent within educational processes?

In competency models, if trainees show competence in all of the listed areas, they can finish their training sooner. This aspect of competencybased education has been reported as a theoretical advantage in the literature ${ }^{8}$ it is now a real possibility in at least one Canadian program as part of a pilot being run by the orthopedic training program at the University of Toronto. ${ }^{9}$ This potential "efficiency" might lead to another challenge: less time for learners to master the subtle but essential aspects of medicine that are currently undefined because physicians may absorb them through acculturation over time..$^{10}$ Living within medical culture, physicians take these so much for granted that they can be hard to identify - without careful study now, it is possible that physicians will only be able to name them after realizing what has been lost with shorter training periods.

Physicians are bound by the dictum primum non nocere (first, do no harm). How can the medical education community follow this dictum during this major educational change? It requires three things: to be cautious about new curricular models and not simply assume that they should be better; to avoid limiting evaluation efforts of the new curricular approaches to small facets of their implementation; and to be open to the idea that - no matter how enticing, logical or intellectually appealing an approach appears to be there may be challenges that cannot be ignored.

There are faults in traditional models for medical education, but educators should not become so invested in new models that they fail to undertake a thorough evaluation of potential unintended consequences. As we reform the educational approaches that will shape the next generation of doctors, we must employ intellectual humility, curiosity and open-mindedness to best serve our profession and our patients.

\section{References}

1. Albanese MA, Mejicano G, Mullan P, et al. Defining characteristics of educational competencies. Med Educ 2008;42:248-55.

2. Frank JR, editor. The CanMEDS 2005 physician competency framework. Better standards. Better physicians. Better care. Ottawa: Royal College of Physicians and Surgeons of Canada; 2005. Available: www.royalcollege.ca/portal/page/portal/rc /common/documents/canmeds/resources/publications/framework _full_e.pdf (accessed 2014 Nov. 17).

3. The College of Family Physicians of Canada. Triple C competency-based curriculum: report of the Working Group on Postgraduate Curriculum Review: part 1. Mississauga (ON): The College of Family Physicians of Canada; 2011. Available: www.cfpc.ca/uploadedFiles/Education/_PDFs/WGCR_TripleC Report_English_Final_18Mar11.pdf (accessed 2014 Nov. 17).

4. Whitehead C, Kuper A, Webster F. The conceit of curriculum. Med Educ 2012;46:534-6.

5. Glover Takahashi S, Bates J, Verma S, et al. Environmental scan synthesis report. Ottawa: Association of Faculties of Medicine of Canada; 2011. Available: www.afmc.ca/pdf/fmec /Synthesis-Report.pdf (accessed 2014 Nov. 17).

6. Kuper A, D'Eon M. Rethinking the basis of medical knowledge. Med Educ 2011;45:36-43.

7. Kuper A, Reeves S, Albert M, et al. Assessment: Do we need to broaden our methodological horizons? Med Educ 2007;41: 1121-3.

8. Frank JR, Snell LS, Ten Cate O, et al. Competency-based medical education: theory to practice. Med Teach 2010;32:638-45.

9. Alman BA, Ferguson P, Kraemer W, et al. Competency-based education: a new model for teaching orthopaedics. Instr Course Lect 2013;62:565-9.

10. Hodges BD. A tea-steeping or i-Doc model for medical education? Acad Med 2010;85(Suppl):S34-44.

Affiliations: Wilson Centre (Kuper, Whitehead), University Health Network - University of Toronto; Department of Family and Community Medicine (Whitehead), Department of Medicine (Kuper), Faculty of Medicine, University of Toronto; Centre for Ambulatory Care Education (Whitehead), Women's College Hospital; Department of Medicine (Kuper), Sunnybrook Health Sciences Centre, Toronto, Ont.

Contributors: Cynthia Whitehead drafted the manuscript and Ayelet Kuper critically revised it for important intellectual content. Both of the authors contributed substantially to the conception, design and analysis of the manuscript, approved the final version submitted for publication and agreed to act as guarantors of the work. 